\title{
Design and Development of Darunavir Loaded Self Micro Emulsifying Drug Delivery System using Extreme Vertices Mixture Design in a Quality by Design Framework
}

\author{
Kavitha Arenur Narayana Reddy ${ }^{1, *}$, Janakiraman Kunchithapatham ${ }^{2}$, Raman Dang ${ }^{3}$, Chandramouli \\ Ramnarayanan ${ }^{4}$
}

${ }^{1}$ Department of Pharmaceutics, Krupanidhi College of Pharmacy, Bengaluru, Karnataka, INDIA.

${ }^{2}$ Department of Pharmacy, Faculty of Engineering and Technology, Annamalai University, Chidambaram, Tamil Nadu, INDIA.

${ }^{3}$ Principal, KLE College of Pharmacy, Bengaluru, Karnataka, INDIA.

${ }^{4}$ Department of Quality Assurance, Krupanidhi College of Pharmacy, Bengaluru, Karnataka, INDIA.

\begin{abstract}
Aim: The therapeutic utility of many poorly water-soluble drugs are severely restricted for their bioavailability. The present study was aimed to development of self-micro emulsifying drug delivery (SMEDDS) system for a poorly water soluble anti-retroviral drug - Darunavir by the application of Quality by Design $(\mathrm{ObD})$ to increase its bioavailability. Methodology: Extreme Vertices Mixture Design (EVMD), based on its utility and the applicability to the formulation problem in hand was selected for the study. The different responses selected for this design were drug release in $15 \mathrm{~min}(\%)$, drug loading $(\mathrm{mg} / \mathrm{ml})$, emulsification time (seconds) and droplet size $(\mathrm{nm})$. The factors or the independent variables considered in the design are oil, surfactant and cosurfactant. Ten different formulations were prepared and evaluated to check the model fit. The optimization and model verification were done by conducting experimental runs. Results: The studies revealed that application of EVMD and development of the formulation in a $\mathrm{QbD}$ framework resulted in a robust and sustainable method for improving the bioavailability of the drug as evidenced by the characterization studies of optimized batch In vitro drug release in $15 \mathrm{~min}(92.43 \%)$, drug loading $(98.95 \mathrm{mg} / \mathrm{ml})$, emulsification time $(31.5 \mathrm{sec})$ and droplet size $(222.2 \mathrm{~nm})$. The Transmission electron micrographs (TEM) obtained for optimized formulation showed a uniform spherical morphology. Conclusion: The development of hard to achieve formulation techniques like SMEDDS involving BCS class 2 and 4 drugs can be sustainably achieved with minimal time and resources, matching regulatory requirements can be attained by the application of EVMD, under $\mathrm{QbD}$ framework.
\end{abstract}

Key words: Antiretroviral, Darunavir, Extreme vertices, Self-emulsified system, QbD.

\section{INTRODUCTION}

Human Immunodeficiency Virus (HIV) incapacitates T-immune cells (CD4 cells) in the human body and alters the entire immune system. The untreated HIV infection may progress to advanced disease stage called Acquired Immuno Deficiency Syndrome (AIDS). The antiretroviral treatment fights against the HIV and reduces the spreading of virus throughout the body. The highly active antiretroviral therapy also known as combination antiretroviral therapy (cART) is effectively used in the treatment of HIV/ AIDS. ${ }^{1}$ cART involves use of various ARTs like protease inhibitors, integrase inhibitors, nucleotide reverse transcriptase inhibitor, non-nucleotide reverse transcriptase inhibitor and entry inhibitors. Darunavir (DRV) is the last USFDA approved second generation protease inhibitor. ${ }^{2}$ DRV belongs to Biopharmaceutical Classification System (BCS) II, the
Submission Date: 30-09-2019; Revision Date: 26-12-2019; Accepted Date: 24-01-2020

DOI: 10.5530/ijper.54.2.39 Correspondence: Ms. Kavitha Arenur Narayana Reddy, Department of

Pharmaceutics, Krupanidhi College of Pharmacy, Bengaluru-560035, Karnataka, INDIA. Phone: +91 9986656381 E-mail: kavithareddykcp@ gmail.com

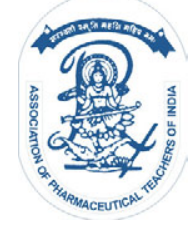

www.ijper.org 
drug with poor aqueous solubility and good permeability characteristics. The poor oral bioavailability of the drug may be due to poor aqueous solubility $(0.15 \mathrm{mg} /$ $\mathrm{ml}$ ) or efflux of absorbed drug back into the intestinal lumen or it can be because of extensive metabolism of drug by the Cytochrome P450 enzyme. The oral bioavailability of the drug is $37 \%$ and on co-administration of the drug with small doses of Cytochrome P450 enzyme inhibitors (Ritonavir/Cobicistat) remarkably improves the oral bioavailability to $82 \%{ }^{3}$ In the present research, the attempt has been made to improve the solubility characteristics of the drug by converting into a lipid based drug delivery system (LBDDS). ${ }^{4}$ Among the LBDDS, Self-emulsifying drug delivery (SEDDS) system is one of the promising delivery system which can enhance the solubility characteristics of DRV and improve oral bioavailability. SMEDDS are the isotropic mixtures of oil, surfactant and cosurfactant and their preconcentrate mixture on oral administration converts into nano/micro emulsion in presence of GI fluids under the mild agitation provided by the GIT. ${ }^{5}$ SEDDS being a formulatory approach not only helps in improving the solubility of the drug to improve the dissolution characteristics but also aids in the lymphatic uptake of the drug, especially for the those drugs which are targeted into the lymphatic system(Chemotherapeutic agents/Anti-retroviral agents). ${ }^{6,7}$ Therefore the attempts were made to convert DRV into a novel SMEDDS.

One factor at time (OFAT) is the conventional formulation development approach. Because of the formulatory complexities involved and the quantum of time and resources utilized by OFAT, this approach is not well appreciated. Well controlled and reproducible results obtained to achieve the required therapeutic goals of the formulation by the systematic approach called Quality by design(QbD). ${ }^{8}{ }^{8}$ DRV loaded SMEDDS formulations were developed and optimized by a Design of Experiments (DOE) approach called Mixture design. ${ }^{10}$ Mixture design is a statistical approach used to select the components (experimental inputs) of the system, which will exert least influence on the product variability. ${ }^{11}$ The mixture design was developed by using JMP ${ }^{\circledR}$ 13.2.1 software (Academic license from SAS, SAS Institute, Cary, NC, USA). The Critical Material Attributes (CMAs) selected for the study were oil (Capryol 90), surfactant (Tween 80) and cosurfactant (Transcutol HP) and the Critical Process Parameters (CPPs) were conditions like stirring speed, type of stirrer and the stirring temperature. The Critical Quality attributes (CQAs) selected for optimization were particle size, emulsification time, drug loading and in vitro drug release study. ${ }^{12,13}$

\section{MATERIALS AND METHODS}

\section{Materials}

Darunavir was received as gift sample from Aurobindo Pharma Ltd, Hyderabad, India. Maisine ${ }^{\circledR} \mathrm{CC}$ (glyceryl monolinoleate NF, HLB-1), Capryol ${ }^{\mathrm{TM}} 90$ (propylene glycol monocaprylate NF, HLB-6), Transcutol ${ }^{\circledR} \mathrm{HP}$ (diethylene glycol monoethyl ether EP/USP NF,HLB-4.2), Labrasol $^{\mathbb{R}}$ (caprylocaproyl poloxyl-8 glycerides NF, HLB-14) and Labrafil ${ }^{\circledR}$ M 1944 CS( Oleoyl polyoxy-6 glycerides, HLB-9) were obtained as gift samples from Gattefosse, Saint-Priest Cedex, France. Tween 80 (Polyoxyethylene sorbitan trioleate, HLB-15), Span 20 (Sorbitan monolaurate, HLB-8.6) and PEG 400 (Polyoxyethylene monooleate, HLB-11.4) were purchased from Sigma-Aldrich, Germany. All other chemicals were of analytical grade.

\section{Methods}

\section{Defining QTPP and CQAs}

The QbD approach advocates the defining of the product performance parameters that will affect the quality of the product, known as Quality Target Product Profile (QTPP). ${ }^{14}$ The QTPP is selected based on the functional attribute of the formulation and also the data obtained from the literature review is taken as a feed forward in defining the QTPP (Table 1). The QTPP describes a concise set of performance requirements (Formulatory, biopharmaceutical and regulatory) that will be crucial for the product quality. Based on the QTPP the CQAs are defined for the product ${ }^{15}$ (Table 2).

\section{Risk assessment}

Risk assessment - a QbD tool for identifying and mitigating the sources of variability that will affect the product consistency and it was constructed to identify the CMAs and CPPs affecting the CQAs of DRV loaded SMEDDS. The cause and effect diagram or Ishikawa diagram was constructed using JMP ${ }^{\circledR}$ software to identify the possible causes and sub causes affecting the CQAs of the product (Figure 4). The factors with the high risk were selected by constructing the Risk Estimation Matrix (REM), which depicts the potential risks associated with the material attributes and the process attributes having a strong influence on the CQAs of the product (Table 3). Each factor was assigned risk grades of low, medium or high. ${ }^{15}$ 


\begin{tabular}{|c|c|c|}
\hline \multicolumn{2}{|c|}{ Table 1: Quality Target Product Profile (QTPP) for Liquid SMEDDS of Darunavir. } \\
\hline QTTP Elements & Target & Justification \\
\hline Dosage type & Lipid based formulation & Bioavailability improvement \\
\hline Dosage form & Capsule & Target dose of $150 \mathrm{mg}$ essential to target viral load \\
\hline Dosage strength & $150 \mathrm{mg}$ & Most convenient route for AIDS patients (Patient acceptability) \\
\hline Route of administration & Oral & Acts as a permeation and photo barrier \\
\hline Packaging & Alu - Alu Blister & For attaining Minimum Inhibitory Concentration in the target site \\
\hline Pharmacokinetic parameters & $\mathrm{T}_{\max }, \mathrm{C}_{\max }, \mathrm{AUC}$ & $\begin{array}{c}\text { To assess degradatory pattern of the Drug and Excipients used in } \\
\text { the formulation. }\end{array}$ \\
\hline Stability & $\begin{array}{c}\text { As per the conditions of ICH Q1B } \\
\text { Long term stability studies }\end{array}$ & \begin{tabular}{l} 
\\
\hline
\end{tabular}
\end{tabular}

\begin{tabular}{|c|c|c|c|c|}
\hline \multicolumn{2}{|c|}{ Quality Attributes of product } & Target & CQA & Justification \\
\hline \multirow{3}{*}{$\begin{array}{l}\text { Physical } \\
\text { attributes }\end{array}$} & Color & \multirow{3}{*}{$\begin{array}{l}\text { Acceptable to } \\
\text { patient }\end{array}$} & \multirow[t]{3}{*}{ No } & \multirow{3}{*}{$\begin{array}{l}\text { The physical attributes were not directly related to the efficacy and } \\
\text { safety of the product, since the product will be enclosed in a capsule } \\
\text { shell, it has no bearing on the elegance. }\end{array}$} \\
\hline & Odor & & & \\
\hline & Appearance & & & \\
\hline \multicolumn{2}{|c|}{ Drug content (mg) } & $\begin{array}{l}\text { NLT } 150 \text { mg per unit } \\
\text { dose }\end{array}$ & Yes & $150 \mathrm{mg}$ per unit dose essential to combat the CD4 viral load \\
\hline \multicolumn{2}{|c|}{ Transmittance (\%) } & $>95 \%$ & Yes & Clarity of the product ensures the minimization of the globule size \\
\hline \multicolumn{2}{|c|}{ Globule size (nm) } & $<200 \mathrm{~nm}$ & Yes & $\begin{array}{c}\text { Smaller and consistent globule size essential for stability and } \\
\text { bioavailability of the formulation. }\end{array}$ \\
\hline \multicolumn{2}{|c|}{ Zeta potential (mEv) } & Stearically stable & Yes & $\begin{array}{l}\text { Target zeta potential essential to ensure stability of the dispersed } \\
\text { system }\end{array}$ \\
\hline \multicolumn{2}{|c|}{$\begin{array}{l}\text { Emulsification efficiency } \\
\text { (seconds) }\end{array}$} & $<120$ & Yes & $\begin{array}{l}\text { Has direct correlation with onset of action and influences the size of the } \\
\text { dispersed globules }\end{array}$ \\
\hline \multicolumn{2}{|c|}{ Drug release in $15 \mathrm{~min}$} & $>70 \%$ & Yes & Has direct correlation with bioavailability \\
\hline \multicolumn{2}{|c|}{ Permeability (45 mins) } & NLT 45 mins & Yes & $f \geq 80 \%$ \\
\hline
\end{tabular}

NLT - not less than

\begin{tabular}{|c|l|c|c|c|c|c|}
\hline \multicolumn{7}{|c|}{ Table 3: REM Matrix. } \\
\hline $\begin{array}{c}\text { CMA /CPP } \\
\text { CQAs }\end{array}$ & Oil & Surfactant & Cosurfactant & Stirring speed & Stirring time & $\begin{array}{c}\text { Stirring } \\
\text { temperature }\end{array}$ \\
\hline Drug loading & High & High & High & Low & Low & Low \\
\hline Droplet size & High & High & High & Medium & Medium & Medium \\
\hline Zeta potential & High & High & High & Low & Low & Low \\
\hline Emulsification Time & High & High & High & Medium & Medium & Medium \\
\hline Drug release in 15 min & High & High & High & Low & Low & Low \\
\hline Permeability (45 mins) & High & High & High & Low & Low & Low \\
\hline
\end{tabular}

\section{Solubility study}

The formulation development began with the selection of SMEDDS components based on the maximum solubility of DRV in various oils, surfactant and cosurfactant. Different oils, surfactant and cosurfactant such as Capryol 90, Maisine CC, Labrafil M 1944 CS, Tween 80, Labrasol, Span 20, PEG 400 and Transcutol HP were screened. An excess amount of DRV was introduced into an Eppendorf tube containing $2 \mathrm{ml}$ of vehicle and agitated in vortex shaker for $10 \mathrm{~min}$. After mixing, the
Eppendorf tubes were kept in mechanical shaker for 48 $\mathrm{hr}$ at room temperature. After attaining the equilibrium the mixtures were subjected to centrifugation at 3000 rpm for $15 \mathrm{~min}$. The supernatant was transferred to another Eppendorf tube and filtered through a $0.45 \mu \mathrm{m}$ Millipore ${ }^{\circledR}$ filter. The filtered solutions were diluted suitably with methanol and the absorbance was determined by using UV spectrophotometer (UV 1800, Shimadzu) at $\lambda_{\text {max }} 264 \mathrm{~nm} .{ }^{16}$ All measurements were done in triplicate and the solubility was expressed as the mean value $(\mathrm{mg} / \mathrm{ml}) \pm \mathrm{SD} \cdot{ }^{17}$ 


\section{Pseudo ternary phase diagram}

The pseudo ternary phase diagram was constructed by using ProSim ${ }^{\circledR}$ ternary plot software. The water titration method was used to investigate concentration range of oil, surfactant and cosurfactant, which could give the boundaries for nano/micro emulsion region. The oils (Capryol 90 and Maisine CC), surfactant (Tween 80) and cosurfactant (Transcutol HP) were selected based on the preliminary solubility studies with drug. The selected surfactant and cosurfactant (Smix) were mixed in different ratios (2:1 and 3:1). For each phase diagram, oil: Smix ratio were mixed thoroughly in the varying proportion of 1:9, 2:8, 3:7, 4:6, 5:5, 6:4 7:3, 8:2 and 9:1 in test tubes. These mixtures were homogenized in a vortex mixer (Spinix) for homogenization. The aqueous phase (double distilled water) was added in increments of $5 \%$ in the range of 5 to $95 \%$ of total volume. After each addition, the mixtures were vortexed for $2 \mathrm{~min}$ in vortex mixer and allowed to equilibrate. ${ }^{18}$

\section{Mixture Design}

Mixture design is a type of statistical experimental design used for the development and optimization of formulations. Mixture design is used in pharmaceutical product development when the factors are proportion of blend. ${ }^{19} \mathrm{~A}$ variant of Mixture design namely, Extreme vertices Mixture design (EVMD) is a constrained mixture design, where the mixture components are subjected to constraints such as maximum or minimum value for each component. ${ }^{20}$ The components of the mixture are expressed as fractions which sums to $1(100 \%)$. The measured response in the mixture experiments depends only on the relative proportion of the ingredients. The main purpose of the mixture design is to mathematically model the ratios of the blend to predict the response(s) for any mixture in the design and measure the influence of each factor alone or in combination with other factors on the response(s) ${ }^{21,22}$ In this work a SMEDDS formulation development and optimization was done through EVMD. The CQAs identified were factored as responses or dependent variables selected for the study. They are droplet size (nm), emulsification time (seconds), drug solubility in the mixture $(\mathrm{mg} / \mathrm{ml})$ and in vitro drug release in 15 min (\%). The CMAs (factors) or independent variables selected for the study are oil (Capryol 90), Surfactant (Tween 80) and Cosurfactant (Transcutol HP).

The CPP were not factored in the design consideration because of their minimal influence on the responses as evinced by the REM. The mixture design obtained by using JMP ${ }^{\circledR}$ 13.2.1 software. The responses (dependent variables) and factors with constrains (independents variables) are listed in the Table 4 and 5 . The different formulations (Table 6) obtained as per the design are subjected to characterization. The overview of the $\mathrm{QbD}$ processes in devising the mixture design is as per the Table 7.

\section{Preparation of SMEDDS formulations}

SMEDDS formulations were prepared by using varying the proportion of Capryol 90, Tween 80 and Transcutol $\mathrm{HP}$ as per the EVMD. The details of various formulations with different components mixture are presented in the Table 6. The ten different formulations (F1-F10) were prepared by dissolving $100 \mathrm{mg}$ of DRV in the mixture of Capryol 90, Tween 80 and Transcutol HP and were heated to $40^{\circ} \mathrm{C}$ in a water bath. The mixture was vortexed by using vertex mixture until it becomes clear and transparent. All formulations were stored in ambient temperature until use. ${ }^{23}$

\section{Droplet size analysis}

The formulations were diluted with double distilled water at the ratio of $1: 100(\mathrm{v} / \mathrm{v})$ in volumetric flask

Table 4: Composition and limits of experimental domain.

\begin{tabular}{|c|c|c|c|}
\hline \multirow{2}{*}{ Factors } & \multirow{3}{*}{ Role } & \multicolumn{2}{|c|}{ Values } \\
\cline { 3 - 4 } & & Low & High \\
\hline Capryol 90 & Mixture & 0.12 & 0.32 \\
\hline Tween 80 & Mixture & 0.51 & 0.67 \\
\hline Transcutol HP & Mixture & 0.18 & 0.23 \\
\hline
\end{tabular}

\begin{tabular}{|c|c|c|c|}
\hline \multicolumn{3}{|c|}{ Table 5: Responses in mixture design. } \\
\hline Responses & Goal & $\begin{array}{c}\text { Lower } \\
\text { Limit }\end{array}$ & $\begin{array}{c}\text { Upper } \\
\text { Limit }\end{array}$ \\
\hline Drug release in $15 \mathrm{~min}(\%)$ & Maximize & 70 & 100 \\
\hline Drug loading $(\mathrm{mg} / \mathrm{ml})$ & Maximize & 90 & 100 \\
\hline Emulsification time $(\mathrm{seconds})$ & Minimize & 20 & 60 \\
\hline Droplet size $(\mathrm{nm})$ & Minimize & 50 & 300 \\
\hline
\end{tabular}

Table 6: Composition of SMEDDS as per the EVMD.

\begin{tabular}{|c|c|c|c|}
\hline Formulation & Capryol 90 & Tween $\mathbf{8 0}$ & Transcutol HP \\
\hline F1 & 0.26 & 0.51 & 0.23 \\
\hline F2 & 0.285 & 0.51 & 0.205 \\
\hline F3 & 0.15 & 0.67 & 0.18 \\
\hline F4 & 0.19 & 0.58 & 0.23 \\
\hline F5 & 0.135 & 0.67 & 0.195 \\
\hline F6 & 0.31 & 0.51 & 0.18 \\
\hline F7 & 0.12 & 0.66 & 0.22 \\
\hline F8 & 0.23 & 0.59 & 0.18 \\
\hline F9 & 0.12 & 0.65 & 0.23 \\
\hline F10 & 0.12 & 0.67 & 0.21 \\
\hline
\end{tabular}




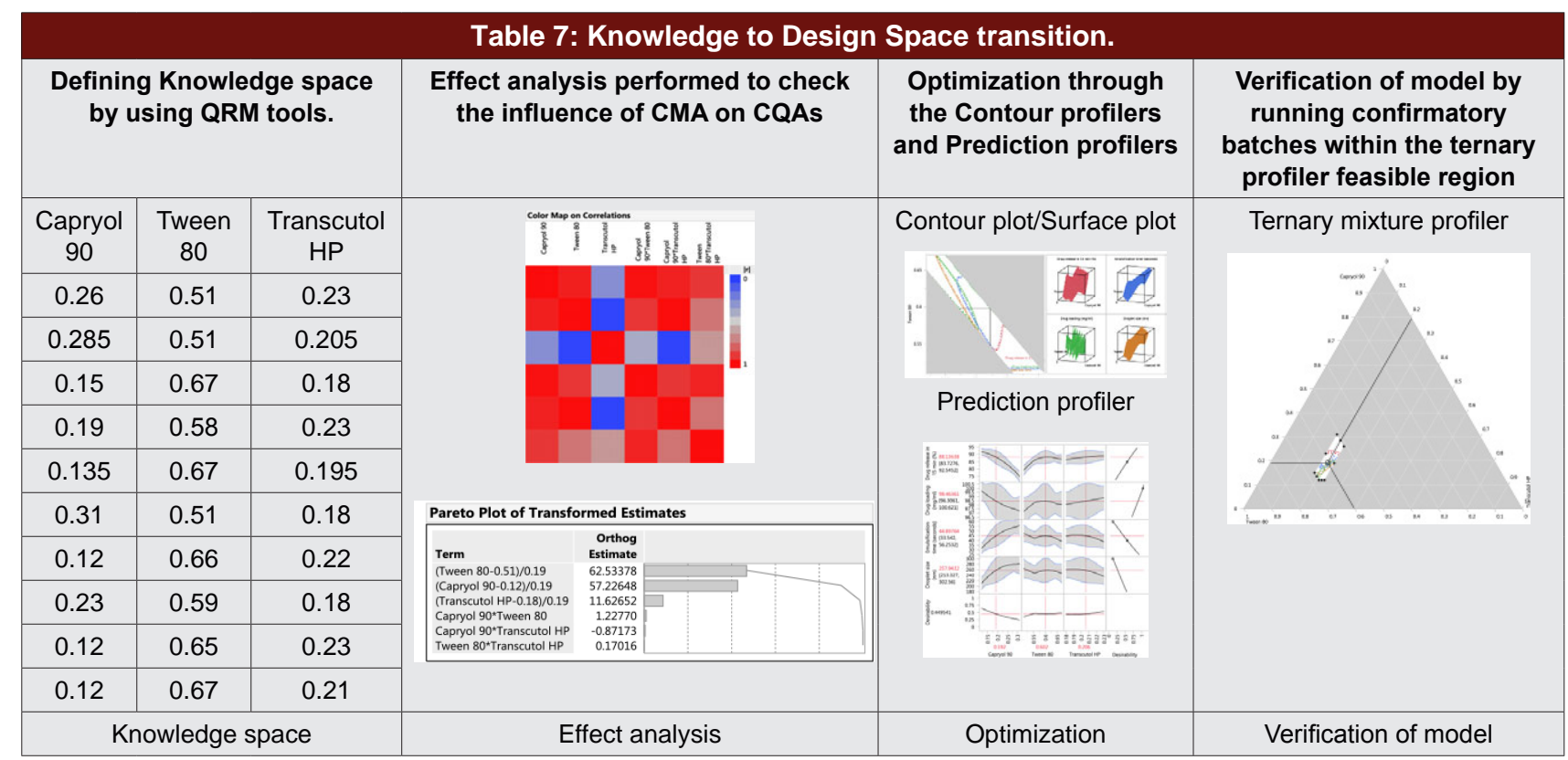

$(100 \mathrm{ml})$ and gently mixed by inverting the flask. The mean droplet size and Poly dispersity index (PDI) of the diluted formulations was determined by photon correlation spectroscopy using Malvern Zetasizer Nano-ZS (Malvern Instruments, United Kingdom). All studies were repeated in triplicate. ${ }^{24}$

\section{Drug loading}

SMEDDS equivalent to $100 \mathrm{mg}$ of DRV was taken and dissolved in small quantity of methanol. The volume was made up to $100 \mathrm{ml}$ with double distilled water. $0.2 \mathrm{ml}$ was withdrawn from the stock solution and diluted up to $10 \mathrm{ml}$ with double distilled water. The resultant solution absorbance was measured at $264 \mathrm{~nm}$ by using UV spectrophotometer (UV 1800, Shimadzu). The drug content study was carried out in triplicates. ${ }^{25}$

\section{Emulsification time}

Self-emulsification properties of the prepared formulations were assessed by using USP Type II dissolution apparatus (LABINDIA, DS 8000, Mumbai, India). $1 \mathrm{ml}$ of the formulation was added drop wise into $500 \mathrm{ml}$ of double distilled water maintained at $37 \pm 0.5^{\circ} \mathrm{C}$, under mild agitation provided by the rotating paddle $(50 \mathrm{rpm})$. The time taken (seconds) by each formulation for the formation of a clear homogenous system was noted in triplicates. Based on the final appearance of the product the emulsified formulations were graded as per following grading system. ${ }^{26,27}$

Grade A: A clear bluish emulsion obtained within 1 min.

Grade B: Slightly clear bluish white emulsion formed within $1 \mathrm{~min}$.
Grade C: Milky emulsion obtained within 2 min. Grade D: A dull grayish emulsion with oily appearance and emulsification process takes more than 2 min.

Grade E: Poorly emulsified formulation with large oil globules floating on the surface.

\section{In-vitro Dissolution Test}

Dissolution studies were performed according to the method prescribed by USFDA. ${ }^{28}$ In-vitro release profiles of the capsules filled with formulations were determined using USP Type II (LABINDIA, DS 8000, Mumbai, India) rotating paddle apparatus at $37 \pm 0.5^{\circ} \mathrm{C}$ and with a rotating speed of $75 \mathrm{rpm}$ in $900 \mathrm{ml}$ of discriminatory medium of Phosphate buffer ( $\mathrm{pH}$ 6.8) with $2 \%$ Polysorbate $20 .{ }^{29}$ The filled capsules were held at the bottom of the vessel using stainless steel sinkers. Aliquots $(3 \mathrm{ml})$ were withdrawn after 5, 10, 15, 20, 30 and $45 \mathrm{~min}$ and filtered using $0.45 \mu \mathrm{m}$ Millipore ${ }^{\circledR}$ filter. The amount of DRV released in the dissolution medium was determined spectrophotometrically at $264 \mathrm{~nm}$. The dissolution experiments were carried out in triplicates.

\section{Model verification and optimization}

The various responses (CQAs) obtained for all the ten formulations were incorporated in the design to check the model fit and for the optimization of formulation components for the desired responses. The simple optimization of the design was done through the contour profilers. The contour profiler report shows a contour profiler plot, surface plot for each response; factor (oil/surfactant/cosurfactant) and response settings and its controls. The inter and intra mixture 
behavior of components towards the individual responses are presented in contour surface plots (Figure 15). The simultaneous optimization of the formulation by mixture design is done by desirability function approach. The overall desirability is obtained from the individual desirability arrived for each response. The global desirability function value ranges from 0 to 1 . The prediction profiler obtained pre and post optimization are presented in the Figure 1 and 2. As per the optimized prediction profiler, the Optimized Formulation (OF) was prepared and evaluated for responses (Table 8). The experimental results obtained for the optimized formulation were compared with the model predicted responses.

The model validation was done through the ternary mixture profiler. The ternary mixture profiler provides the optimal space in the ternary diagram (Figure 3). The different ratio of oil, surfactant and cosurfactant within the optimal space does not affect the dependent variables (Reponses) of the SMEDDS formulation. The confirmation experiment or Verification formulation (VF) was conducted as per the mixture profiler (Table 8). The experimental values obtained for VF were compared with the predicted values. The lack of differences in the variances of observed and predicted responses indicates better goodness of fit.

\section{Transmission Electron Microscopy}

The morphological characterization of the OF-SMEDDS formulation was carried out by High Resolution Transmission electron microscope (HR-TEM). OF-SMEDDS was diluted with double distilled water at the ratio of 1:200 and the emulsified formulation was examined by using HR-TEM (FEI-TECNAI G2-20 TWIN).

\section{RESULTS AND DISCUSSION}

\section{Risk assessment}

The dosage form development under QbD frame work involves evaluation of material as well as process attributes, which has greater influence on the product quality. Through the fish bone diagram (Figure 4) the potential factors affecting the product CQAs were identified. When it comes to SMEDDS preparation, the material attributes like oil, surfactant and cosurfactant/cosolvent have major contribution towards product responses than the process attributes, because the method of preparation is simple. Hence in the present work, the process attributes involved in the SMEDDS preparation like stirring time, temperature and type of stirring was given least preference, because of their minimal contribution towards the prod-
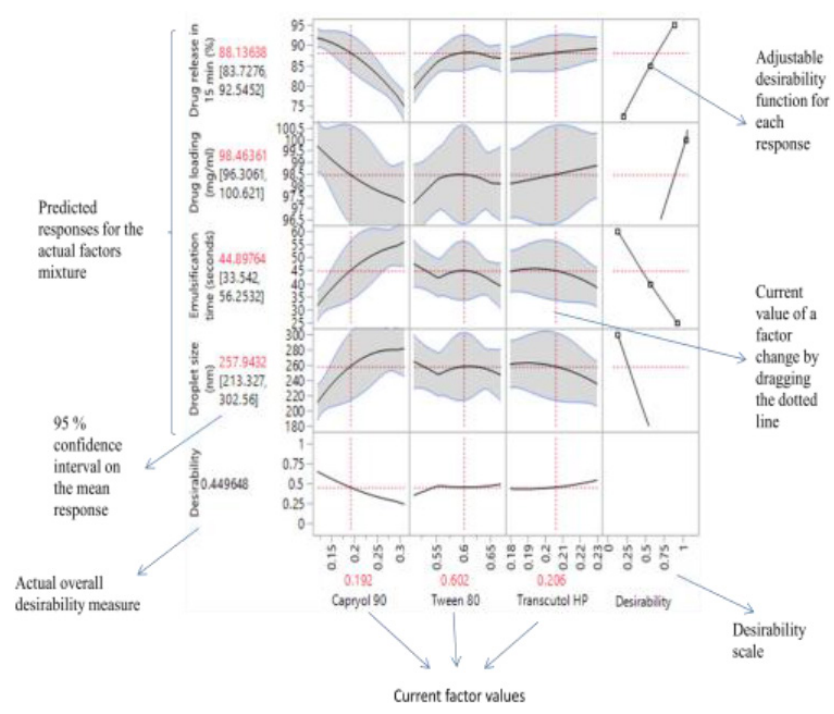

Figure 1: Prediction profiler for multiple responses before optimization.

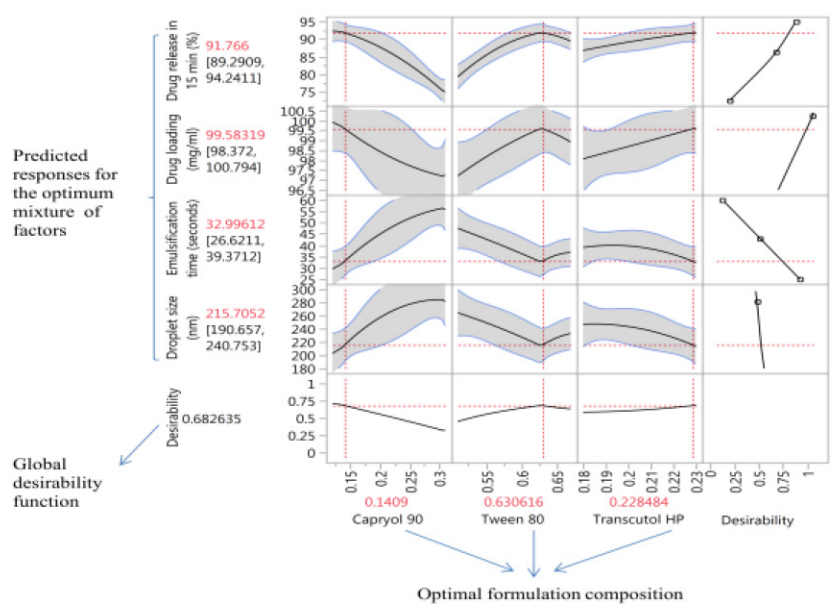

Figure 2: Prediction profiler for multiple responses after optimization.

\begin{tabular}{|c|c|c|c|}
\hline \multicolumn{4}{|c|}{ Table 8: Composition of VF and OF-SMEDDS. } \\
\hline Formulation & Capryol 90 & Tween 80 & Transcutol HP \\
\hline $\begin{array}{c}\text { Verification } \\
\text { formulation (VF) }\end{array}$ & 0.143 & 0.638 & 0.219 \\
\hline $\begin{array}{c}\text { Optimized } \\
\text { Formulation (OF) }\end{array}$ & 0.141 & 0.631 & 0.228 \\
\hline
\end{tabular}

uct variability. Hence the risk associated with process parameters are rated as low (Table 3). The successful development of SEDDS formulation depends on the proper selection of excipients with their relative proportion in the formulation.

\section{Preformulation studies}

The solubility of DRV in various excipients is presented in the Figure 5. Amongst lipids, both Medium chain triglycerides (Capryol90-147.99 $\mathrm{mg} / \mathrm{ml}$ ) and Long chain triglycerides (Maisine CC-35.13 mg/ml) were 


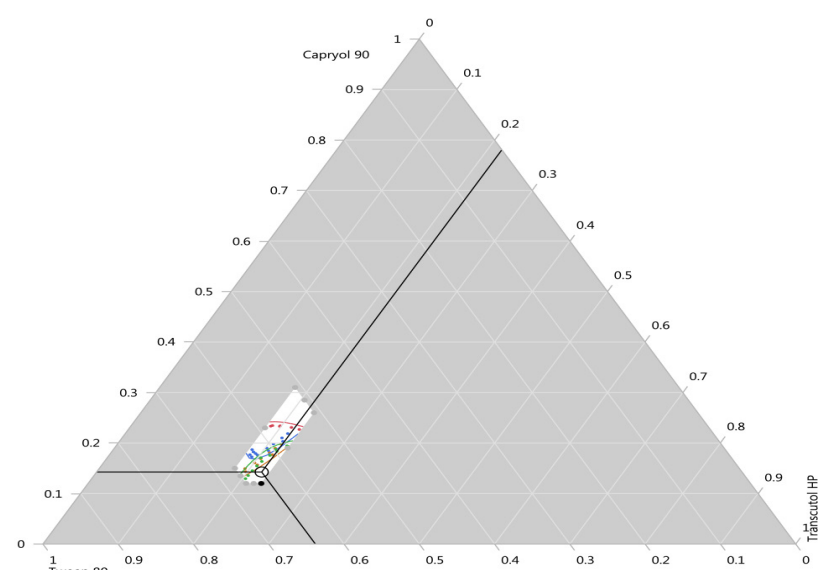

Figure 3: Ternary mixture diagram depicting the design space.

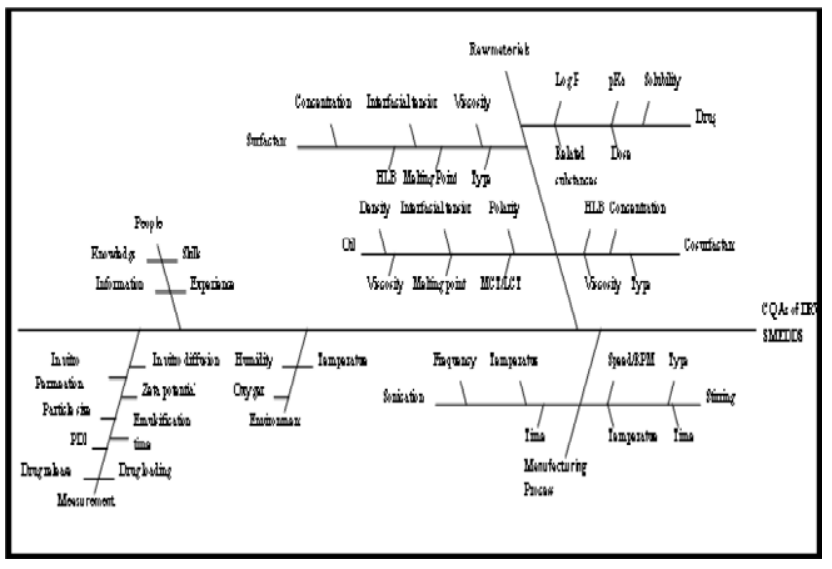

Figure 4: Ishikawa diagram depicting the causes and sub causes affecting quality characteristics of DRV - SMEDDS.

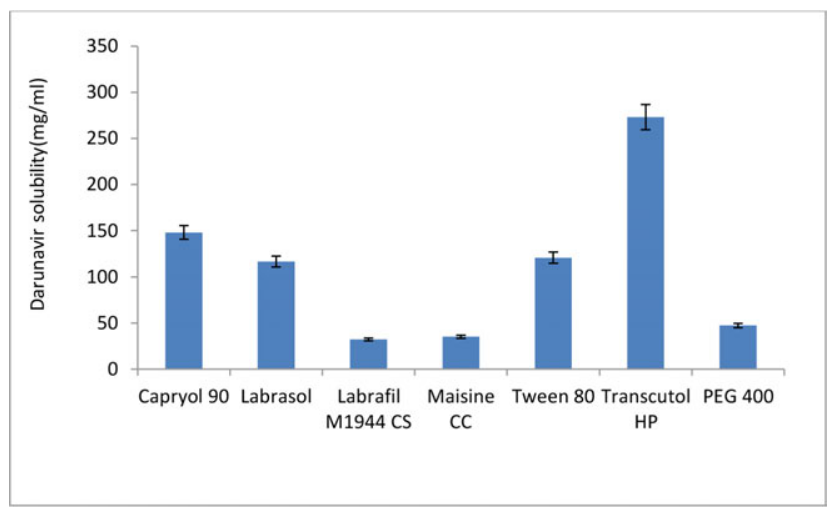

Figure 5: Solubility report for various vehicles (Values are expressed as mean $\pm S D, n=3$ ).

selected as oil phase. Similarly, among various surfactants and cosurfactants, high drug solubility was observed with Tween 80(120.7467 mg/ml) and Transcutol HP $(273.07 \mathrm{mg} / \mathrm{ml})$ respectively. It was observed that Tween 80 in combination with Transcutol at the ratio of 3:1 in combination with Capryol 90 shows better results in terms of clarity as well as accommodating

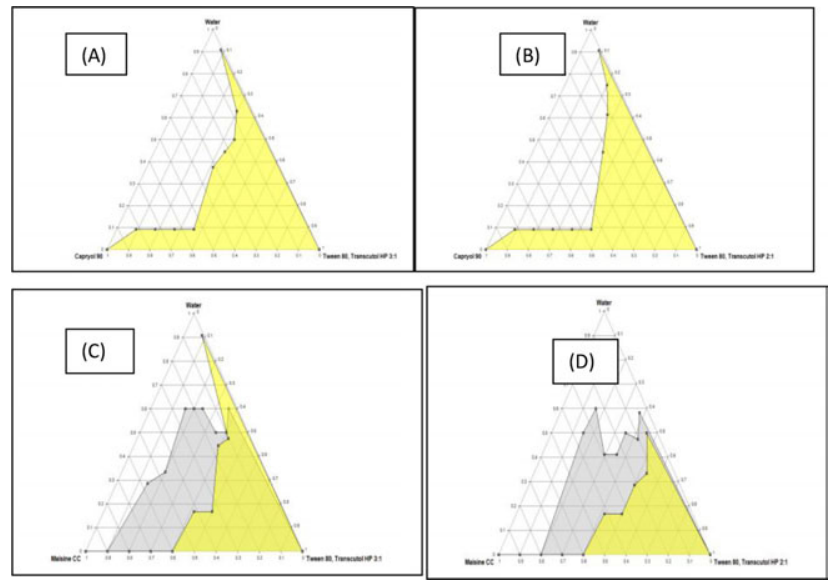

Figure 6: Pseudoternary phase diagrams of SEDDS system containing Capryol 90, Tween 80, Trancutol HP with different Smix ratio of A) 3:1 and B) 2:1, Maisine CC with Tween 80 , Transcutol HP at Smix ratio of C) 3:1 and D) 2:1.

maximum area in phase diagram as compared to $2: 1$ ratio (Figure $6 \mathrm{~A}$ and $\mathrm{B}$ ). The selected Tween 80 (HLB- 15) and Transcutol HP (HLB- 4.2) with high and low HLB values will helps in the formation of stable spontaneous emulsion with fine globule size. Whereas in case of Maisine oil, a thick intermediate gel phase was prominent and minimal region of thermodynamically stable microemulsion was observed in the phase diagram (Figure $6 \mathrm{C}$ and D). Among the various combinations, Capryol 90 with Tween 80 and Transcutol $\mathrm{HP}$ at the Smix ratio of 3:1 was able to give maximal region for stable microemulsion.

\section{Droplet size}

The rate and extent of drug release from the selfemulsified system depend on the mean droplet size of the emulsion; it further leads to better absorption of the drug and improvement in the oral bioavailability of drug product. From the droplet size analysis, it was observed that, the mean droplet size for all the ten formulations were within the range of 188.7 to $290.73 \mathrm{~nm}$ (Table 9). The least droplet size and the largest droplet size were obtained with F9 (Figure 7) and F6 respectively It was observed that, the mean droplet size and the proportion of the surfactant and cosurfactant are inversely proportional and vice versa. The presence of more surfactant in the formulation decreases the droplet size by reducing the interfacial tension due to the formation of closely packed surfactant film in the interface. Polydispersibility Index (PDI) is the dimensionless value which ranges from 0.1 to 1 and it is used to express the droplet size distribution. The value obtained close to zero indicates the homogenous droplets in the dispersion system. More the homogeneity in the formulation better will be the physical stability. The 


\begin{tabular}{|c|c|c|c|c|}
\hline \multicolumn{5}{|c|}{ Table 9: Characterization of DRV- SMEDDS, Values are expressed as mean \pm SD $n .3$} \\
\hline Formulations & $\begin{array}{c}\text { Drug release in 15 } \\
\text { min (\%) }\end{array}$ & Drug loading (mg/ml) & $\begin{array}{c}\text { Emulsification time } \\
\text { (seconds) }\end{array}$ & $\begin{array}{c}\text { Droplet size } \\
(\mathbf{n m})\end{array}$ \\
\hline F1 & $79.91 \pm 0.27$ & $97.44 \pm 0.84$ & $45.67 \pm 1.15$ & $260 \pm 6.11$ \\
\hline F2 & $77.40 \pm 0.01$ & $97 \pm 0.67$ & $55.67 \pm 0.58$ & $278.2 \pm 6.17$ \\
\hline F3 & $86.14 \pm 0.60$ & $98 \pm 0.33$ & $41.33 \pm 0.58$ & $248.53 \pm 10.63$ \\
\hline F4 & $87.11 \pm 0.59$ & $98.44 \pm 0.51$ & $42.33 \pm 0.58$ & $253.67 \pm 4.93$ \\
\hline F5 & $88.80 \pm 0.36$ & $98 \pm 0.33$ & $36.67 \pm 0.57$ & $245.1 \pm 4.2$ \\
\hline F6 & $74.24 \pm 0.36$ & $97.11 \pm 1.07$ & $57 \pm 1.0$ & $290.73 \pm 3.90$ \\
\hline F7 & $90.64 \pm 0.35$ & $99 \pm 0.58$ & $36 \pm 1.0$ & $219.9 \pm 3.48$ \\
\hline F8 & $85.89 \pm 0.72$ & $98.33 \pm 0.33$ & $45.33 \pm 0.58$ & $257 \pm 4.45$ \\
\hline F9 & $93.68 \pm 0.95$ & $100.11 \pm 0.51$ & $26.33 \pm 1.53$ & $188.7 \pm 1.04$ \\
\hline F10 & $89.92 \pm 0.59$ & $100.11 \pm 0.69$ & $34.33 \pm 1.52$ & $227.2 \pm 4.48$ \\
\hline
\end{tabular}

PDI values obtained for all the formulations were in the range of 0.237 to 0.499 and indicate the formation of uniform emulsions with good stability characteristics.

\section{Drug loading}

The drug content in all the ten formulations was found to be in the range of 97 to $100 \mathrm{mg} / \mathrm{ml}$ (Table 9). All the formulations shows uniform dispersion of the drug. The formulation F9 and F10 shows highest drug content among all the formulations, this may be due to highest amount of surfactant and cosurfactant present in the formulation.

\section{Self-emulsification time}

The self-emulsification report for all the ten formulation batches is presented in the Table 9. All formulations were able to emulsify spontaneously within $1 \mathrm{~min}$. Among all the formulations F2 and F6 showed bluish white appearance and as per the grading system they were graded as B. The bluish white appearance of the formulation was because of presence of higher lipid content in the formulation and the quantities of surfactant/cosurfactant were not sufficient to emulsify the lipid. The remaining eight formulations (F1, F3, F4, F5, F7, F8, F9 and F10) appeared blue in colour after emulsification and they were graded as A. Subsequent to emulsification test all the formulations were observed for $2 \mathrm{hr}$ and showed no turbidity and precipitation of any components of the system.

\section{In vitro drug release}

The cumulative drug release studies of all the ten were performed and the data obtained is presented in the Table 9. The release profile (Figure 8 ) indicates that all the ten formulations release more than $74 \%$ of drug within $15 \mathrm{~min}$. Among all the ten formulation the maximum drug release of $93.68 \%$ was observed with F9, whereas least percentage release of $74.24 \%$ was

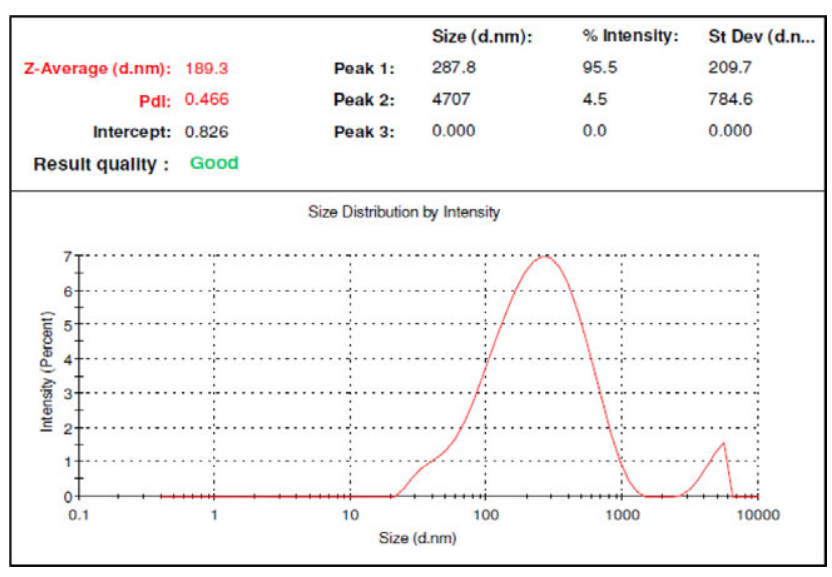

Figure 7: Droplet size and PDI report for F9.

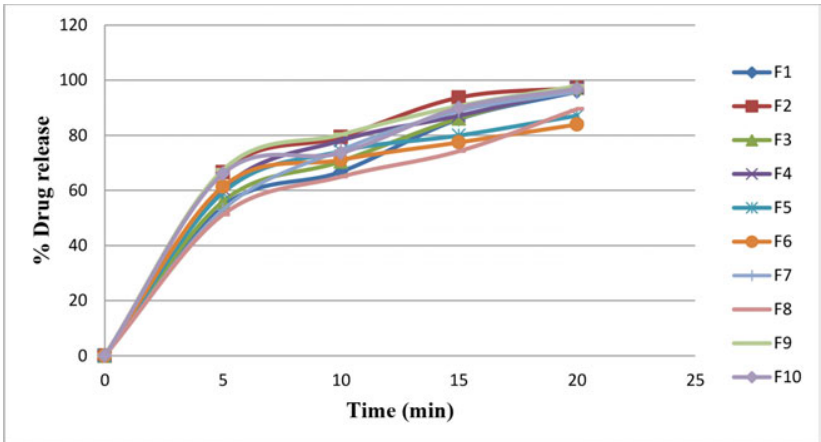

Figure 8: Drug release profile.

obtained with F6 formulation. The enhanced release of DRV from the formulation is because of spontaneous emulsification resulting in smaller droplet size and miscellar solubilization and / or enhanced contact surface might be responsible for increase drug release from the formulations.

\section{Design verification and Optimization of formulation}

The design evaluation was done initially by the color map correlation. The color map obtained for the 
SMEDDs components is presented in the Figure 9. The color map was used to estimate the effect of each factor alone or in combination with other factors on the required responses. The bright red areas represents the most effective combination, whereas the deep red, gray and blue colors are listed in descending order of effectiveness in attaining the required responses. Thus, the color map depicts, the design is suitable for screening of factors in order to obtain the SMEDDS formulations, which meet all the predetermined quality characteristics.

The data obtained from all the ten batches of SMEDDS formulation was analyzed statistically by fitting multiple regression models with the intercept set to zero. The statistically significant models were determined for $\%$ drug release in $15 \mathrm{~min}$, drug loading $(\mathrm{mg} / \mathrm{ml})$, emulsification time (sec) and droplet size (nm). The adjusted $\mathrm{R}^{2}$ and $p$-value obtained for all the responses is used to evaluate the model fit. The prediction plots obtained for all the four responses is presented in the Figure 10. The predictive models, \% drug release in $15 \mathrm{~min}$ $\left(R^{2}=0.98\right.$ and $\left.\mathrm{p}-0.0022\right)$, drug loading $\mathrm{mg} / \mathrm{ml}\left(\mathrm{R}^{2}=0.83\right.$ and $\mathrm{p}-0.1066)$, emulsification time $(\mathrm{sec})\left(R^{2}=0.94\right.$ and $\mathrm{p}-0.0173)$ and droplet size $(\mathrm{nm})\left(\mathrm{R}^{2}=0.90\right.$ and $\left.p-0.0429\right)$ were statistically significant. For the same model the effect test is used to check the fixed effects in the model. The effects test report ( $p$ - value) obtained for all the responses is presented in the Figure 11. The actual vs. predicted values and effects test report obtained for the CQAs has a close numerical immediacy, representing the validity of the model. The contour and surface plot obtained for each response is presented in Figure 12.

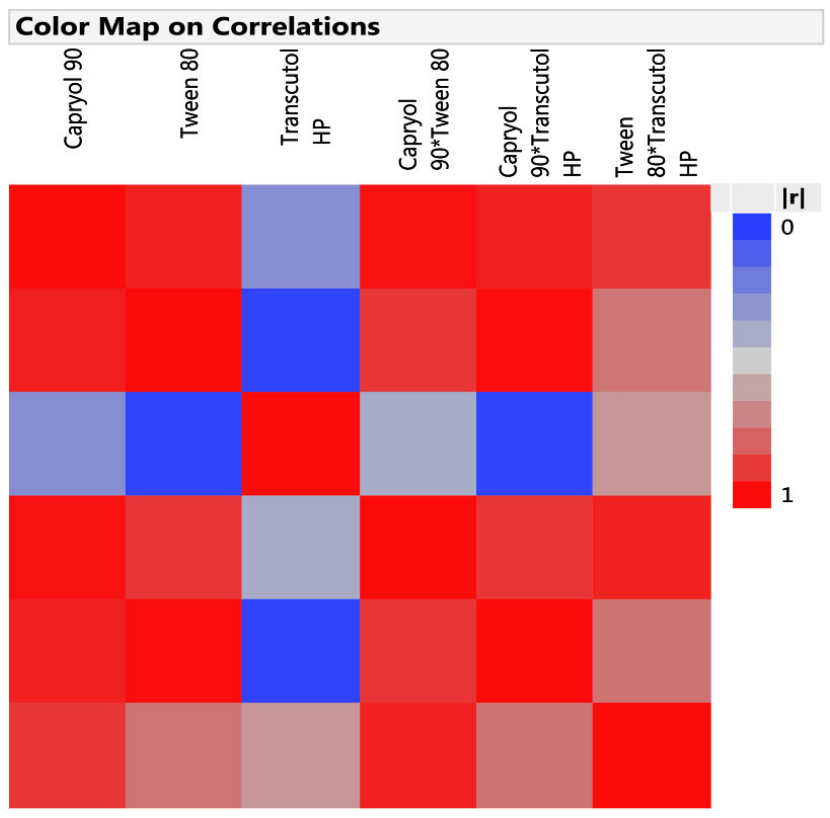

Figure 9: Color map correlation for the screen factors.
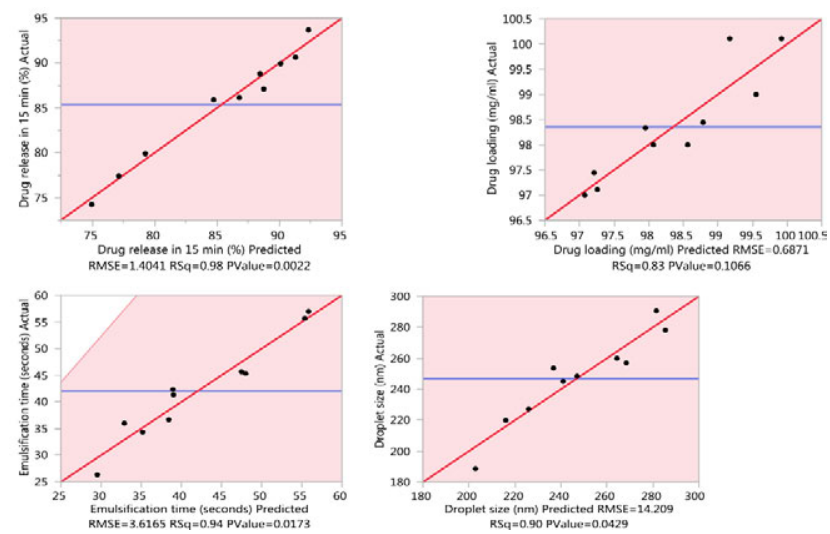

Figure 10: Actual Vs predicted plots for different responses.

\begin{tabular}{|l|r|}
\hline \multicolumn{2}{|c|}{ \% Drug release in 15 min } \\
\hline Source & Prob > F \\
\hline (Capryol 90-0.12)/0.19 & \\
\hline (Tween 80-0.51)/0.19 & \\
\hline (Transcutol HP-0.18)/0.19 & 0.1612 \\
\hline Capryol 90'Tween 80 & $0.0455^{\star}$ \\
\hline Capryol 90Transcutol HP & 0.9870 \\
\hline Tween 80Transcutol HP & 0.7210 \\
\hline
\end{tabular}

\begin{tabular}{|l|r|}
\hline \multicolumn{2}{|c|}{ Drugloading mg $\mathbf{~ m l}$} \\
\hline Source & Prob $>$ F \\
\hline (Capryol 90-0.12)/0.19 & $<.0001^{\star}$ \\
\hline (Tween 80-0.51)/0.19 & $<.0001^{\star}$ \\
\hline (Transcutol HP-0.18)/0.19 & $0.0158^{\star}$ \\
\hline Capryol 90^Tween 80 & 0.6831 \\
\hline Capryol 90^Transcutol HP & 0.8052 \\
\hline Tween 80Transcutol HP & 0.9557 \\
\hline
\end{tabular}

\begin{tabular}{|l|r|}
\hline \multicolumn{2}{|c|}{ Emulsification time in sec } \\
\hline Source & Prob $>$ F \\
\hline (Capryol 90-0.12)/0.19 & $<.0001^{\star}$ \\
\hline (Tween 80-0.51)/0.19 & $0.0028^{\star}$ \\
\hline (Transcutol HP-0.18)/0.19 & 0.3791 \\
\hline Capryol 90Tween 80 & 0.8754 \\
\hline Capryol 90Transcutol HP & 0.3056 \\
\hline Tween 80Transcutol HP & 0.3523 \\
\hline
\end{tabular}

\begin{tabular}{|l|r|}
\hline \multicolumn{2}{|c|}{ Droplet Size in nm } \\
\hline Source & Prob > F \\
\hline (Capryol 90-0.12)/0.19 & $<.0001^{\wedge}$ \\
\hline (Tween 80-0.51)/0.19 & $0.0004^{2}$ \\
\hline (Transcutol HP-0.18)/0.19 & 0.5855 \\
\hline Capryol 90² Tween 80 & 0.7751 \\
\hline Capryol 90^Transcutol HP & 0.3715 \\
\hline Tween $80^{\wedge}$ Transcutol HP & 0.4844 \\
\hline
\end{tabular}

Figure 11: Effect test report.

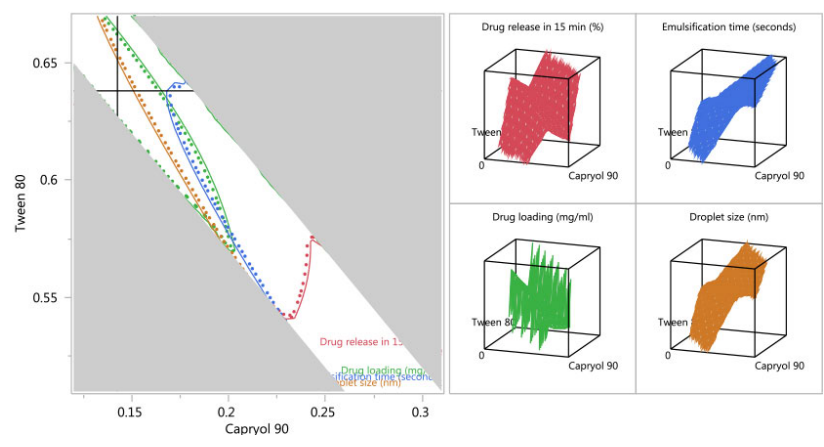

Figure 12: Contour and surface plots showing the effect of formulation components on the responses.

The shaded area in the contour plot region of the graph represents the non-viable region of the design and the white region provides the optimized operational design space.

The predicted and the experimental values obtained for the VF and OF-SMEDDS did not vary significantly (Table 10). The $\%$ difference obtained for both VF and OF were within 5\% deviation. The droplet size, PDI and zeta potential obtained for both VF (Figure 13 and 14) 


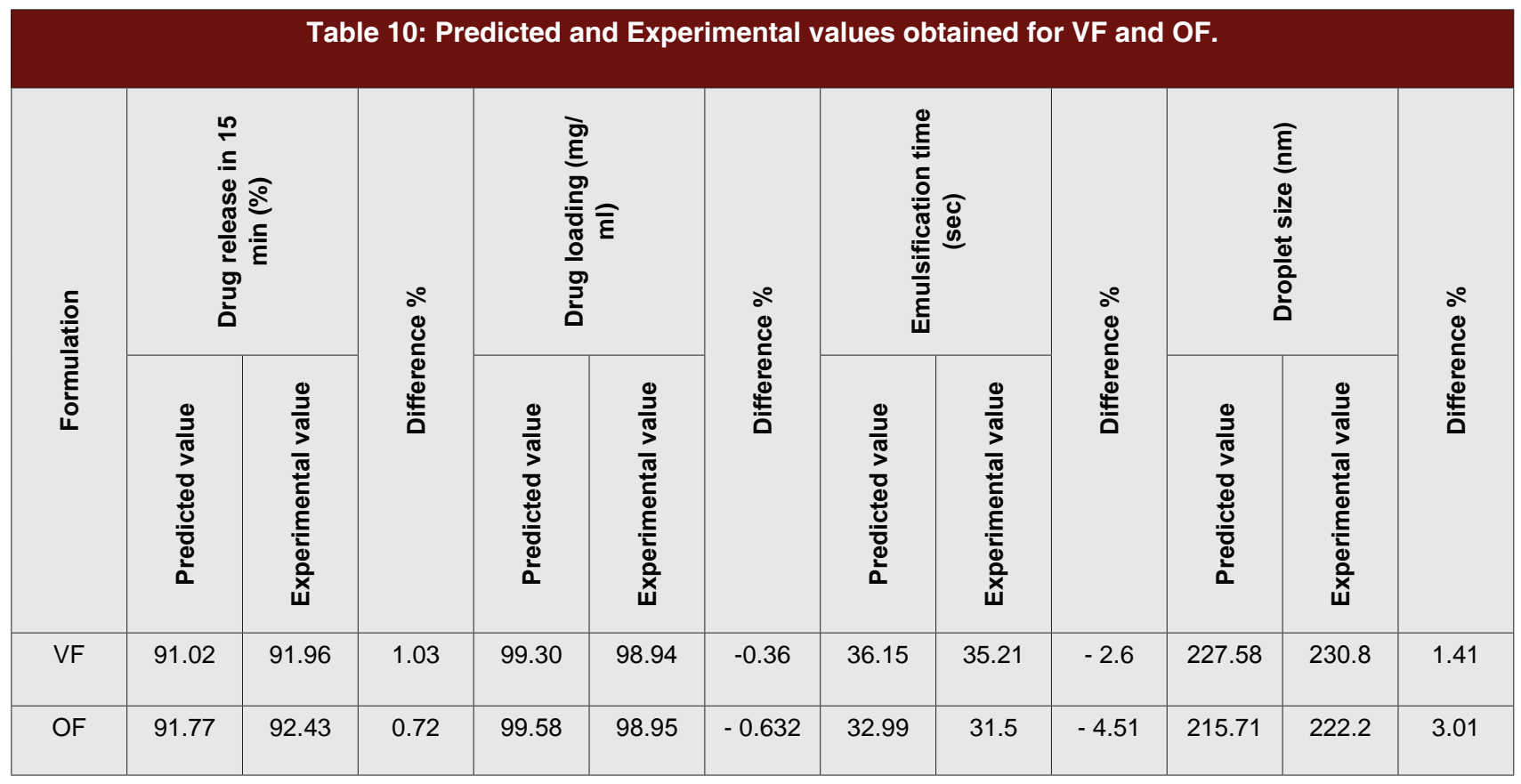

Difference $\%=[($ Experimental value - Predicted value $) /($ Predicted value $)] \times 100$

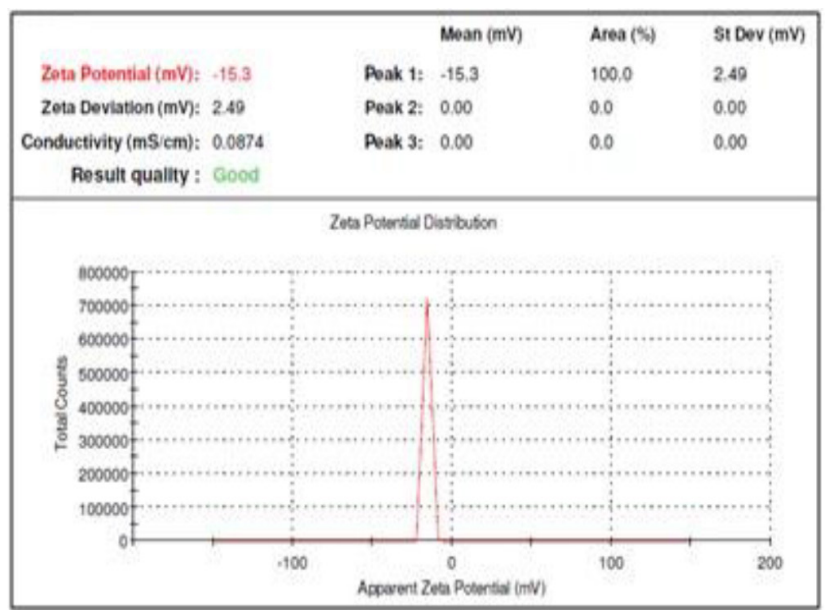

Figure 13: Zeta potential report for the VF-SMEDDS.

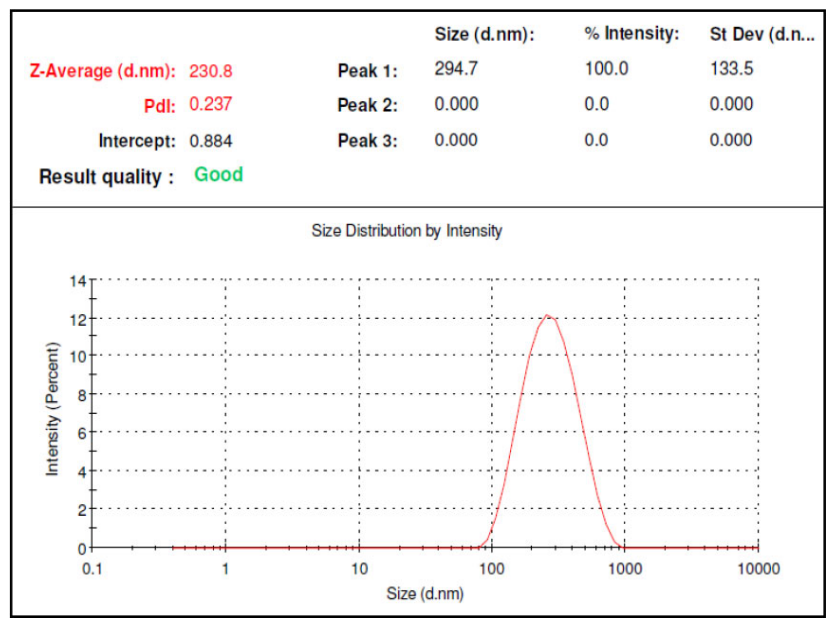

Figure 14: Droplet size and PDI report for the VF-SMEDDS.

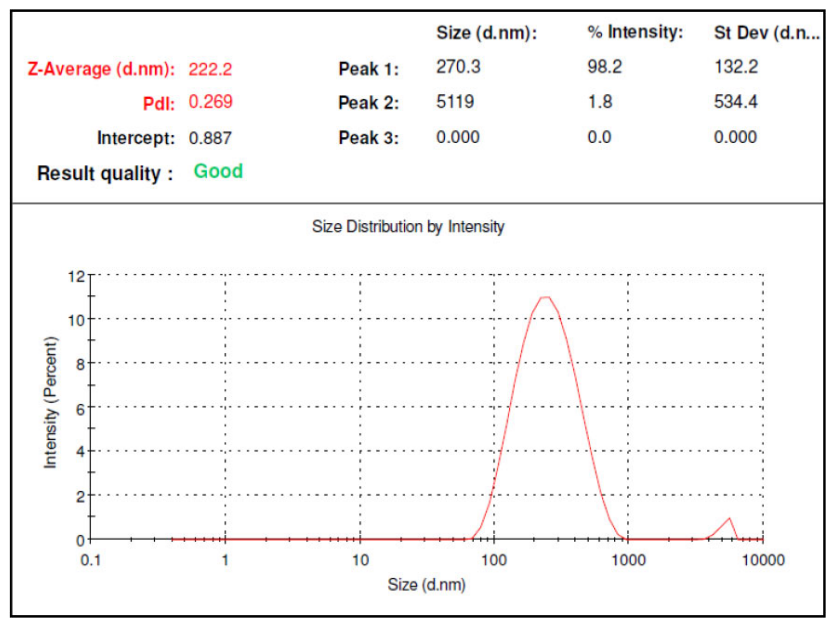

Figure 15: Droplet size and PDI report for the OF-SMEDDS.

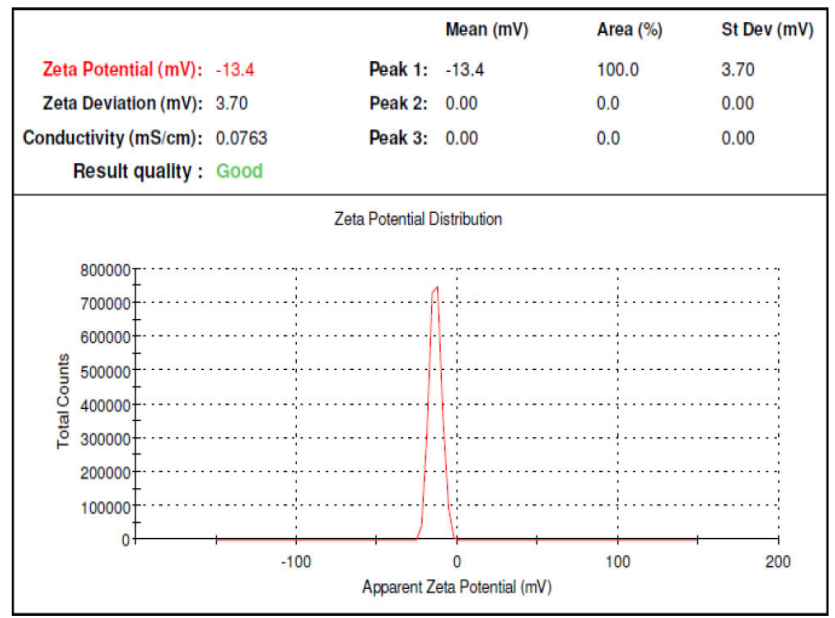

Figure 16: Zeta potential report for the OF-SMEDDS. 


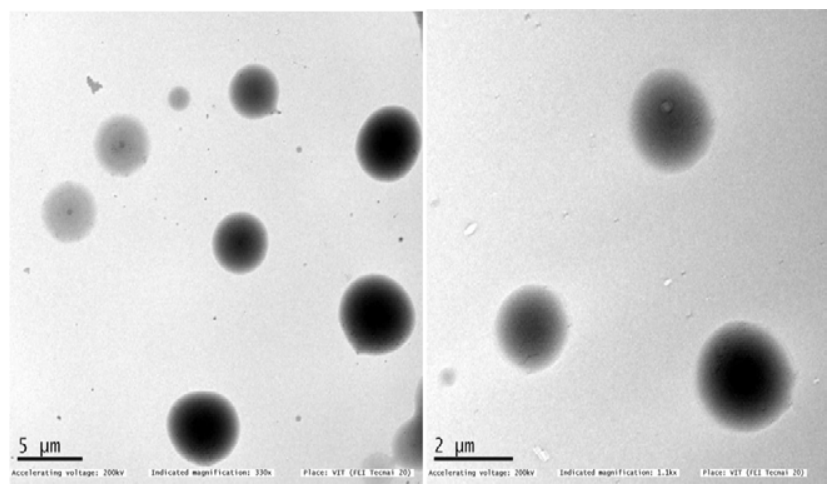

Figure 17: Transmission Electron Microscopy (TEM) image of the OF-SMEDDS.

and $\mathrm{OF}$ (Figure 15 and 16) formulations ensure formation of SMEEDS with good stability characteristics.

\section{Transmission Electron Microscopy}

Figure 17 depicts the TEM images of OF-SMEDDS. The image obtained shows that the emulsified globules were spherical and uniform in shape and size, indicative of physical stability of microemulsion.

\section{CONCLUSION}

The application of $\mathrm{QbD}$ framework and $\mathrm{DoE}$ to achieve therapeutic and formulator goals has become the standard paradigm for formulation development and evaluation. The application of QbD methodology and its associated application of EVMD has resulted in the successful formulation and characterization of DRV in the form of SMEDDS. This lean approach to formulation development done found to be consistent robust and can match its pre-defined CQAs.

\section{ACKNOWLEDGEMENT}

The authors are grateful to Aurobindo Pharma Ltd, Hyderabad, India for providing the gift sample of Darunavir. Gattefosse, Saint-Priest Cedex, France is gratefully acknowledged for providing the gift samples of excipients employed during the studies and the management and Principal Krupanidhi College of Pharmacy for providing the facilities to carry out this work.

\section{CONFLICT OF INTEREST}

The authors declare no conflict of interest.

\section{ABBREVIATIONS}

AIDS: Acquired immunodeficiency syndrome; BCS: Biopharmaceutical classification system; cART: Combination antiretroviral therapy; CMA: Critical material attributes; CPP: Critical process parameters; DoE: Design of experiment; DRV: Darunavir; EVMD: Extreme vertices mixture design; HIV: Human immunodeficiency virus; HLB: Hydrophilic lipophilic balance; HR-TEM: High resolution transmission electron microscope; LBDDS: Lipid based drug delivery system; LCT: Long chain triglycerides; MCT: Medium chain triglycerides; OF: Optimized formulation; OFAT: One factor at a time; PDI: Polydispersibility index; QbD: Quality by design; QTPP: Quality target product profile; REM: Risk estimation matrix; SEDDS: Self emulsifying drug delivery system; SMEDDS: Self micro emulsifying drug delivery system; TEM: Transmission electron microscopy; VF: Verification formulation.

\section{REFERENCES}

1. DeClercq E. Antiretroviral drugs. Current Opinion in Pharmacology. 2010;10(5):507-15.

2. Correa JC, Arcy DM, Serra CH, Salgado HR. A Critical Review of Properties of Darunavir and Analytical Methods for its Determination. Critical Reviews in Analytical Chemistry. 2014;44(1):16-22.

3. Rittweger M, Arasteh K. Clinical pharmacokinetics of Darunavir. Clinical Pharmacokinetics. 2007;46(9):739-56.

4. Pouton CW. Lipid formulations for oral administration of drugs: Nonemulsifying, self- emulsifying and self-micro emulsifying drug delivery system. European Journal of Pharmaceutical Sciences. 2000;11:93-8.

5. Zanchetta B, Chaud MV, Santana MH. Self-emulsifying drug delivery system (SEDDS) in pharmaceutical development. Journal Advanced Chemical Engineering. 2015;5:1-7.

6. Kalepu S, Manrhina M, Padavala V. Oral lipid-based drug delivery systemsan overview. Acta Pharmaceutica Sinica B. 2013;3(6):361-72.

7. Driscoll CM. Lipid-based formulations for intestinal lymphatic delivery. European Journal of Pharmaceutical Sciences. 2002;15(5):405-15.

8. Huang J, Kaul G, Cai C, Chatlapalli R, Hernandez-Abad P, Ghosh K, et al. Quality by design case study: An integrated multivariate approach to drug product and process development. International Journal of Pharmaceutics. 2009;382(1-2):23-32.

9. Charoo NA, Shamsher AA, Zidan AS, Rahman Z. Quality by design approach for formulation development: A case study of dispersible tablets. International Journal of Pharmaceutics. 2012;423(2):167-78.

10. Rambali B, Verreck G, Baert L, Massart DL. Itraconazole formulation studies of the melt-extrusion process with mixture design. Drug Development and Industrial Pharmacy. 2003;29(6):641-52.

11. Snee RD. Experimental designs for quadratic models in constrained mixture spaces. Technometrics. 1975;17(2):149-59.

12. Slambulchilar Z, Valizadeh $H$, Zakeri-Milani P. Systematic development of DoE optimized SNEDDS of Sirolimus with enhanced intestinal absorption. Journal of Drug Delivery Science and Technology. 2014;24(6):620-7.

13. Zidan AS, Sammour OA, Hammad MA, Megrab NA, Habibi MJ, Khan MA. Quality by design: Understanding the formulation variables of a cyclosporine a self nanoemulsified drug delivery systems by Box- Benhnken design and desirability function. International Journal of Pharmaceutics. 2007; 332(1-2):55-63.

14. Peterson JJ. A Bayesian approach to the ICH Q8 definition of design space. Journal of Biopharmaceutical Statistics. 2008;18(5):959-75.

15. Beg S, Sandhu PS, Batra RS, Khurana RK, Singh B. QbD-based systematic development of novel optimized solid self-nanoemulsifying drug delivery system(S-SNEDDS) of Lovastatin with enhanced biopharmaceutical performance. Drug Delivery. 2015;22(6):765-84.

16. Mohammad AS, Jadhav B, Rajender B, Raheem SA, Bashir MA, Sulthana MA. Optimization of UV Spectrophototmetric Method for Estimation of 
Darunavir in Bulk drug and Tablet formulation. International Journal of Pharmaceutical Science and Technology. 2016;9(4):3345-8.

17. Nasr AM, Gardough AR, Ghonaim HM, Ghorab MM. Design, formulation and in-vitro characterization of Irbesartan solid self-nanoemulsifying drug delivery system (S-SNEDDS) prepared using spray drying technique. Journal of Chemical and Pharmaceutical Research. 2016;8(2):159-83.

18. Reddy MS, Rambabu B, Vijetha KA. Development and evaluation of solid self-nano emulsifying drug delivery system of poorly soluble olmesartan medoxomil by using adsorption on to solid carrier technique. International Journal of Pharmaceutical Sciences and Research. 2018;9(8):3398-407.

19. Goupy J, Creighton L. Introduction to design of experiments with JMP examples. SAS Publishing. 2007

20. Cleland D, Mccluskey A. An extreme vertices mixture design approach to the optimization of 1, 2, 3-trichlorobenzene specific molecularly imprinted polymers. Organic and Bimolecular Chemistry. 2013;11(28):4672-9.

21. Snee RD, Marquardt DW. Extreme vertices design for linear mixture models. Technometrics. 1974;16(3):399-408.

22. Snee RD. Computer-aided design of experiments-some practical experiences. Journal of Quality Technology. 1985;17(4):222-36.

23. Jeevana JB, Sreelakshmi K. Design and evaluation of self-nanoemulsifying drug delivery system of flutamide. Journal of Young Pharmacists. 2011;3(1):4-8.
24. Islambulchilar Z, Vailizadeh H, Zakeri-Milani P. Systematic development of DoE optimized SNEDDS of Sirolimus with enhanced intestinal absorption. Journal of Drug Delivery Science and Technology. 2014;24(6):620-7.

25. Chintalapudi R, Murthy TE, Lakshmi KR, Manohar GG. Formulation, optimization and evaluation of self-emulsifying drug delivery systems of nevirapine. International Journal of Pharmaceutical Investigation. 2015;5(4):205-13.

26. Mahmoud DB, Shukr MH, Bendas ER. In vitro and in vivo evaluation of selfnanoemulsifying drug delivery systems of cilostazol for oral and parenteral administration. International Journal of Pharmaceutics. 2014;476(1-2):60-9.

27. Patel MJ, Patel SS, Patel NM, Patel MM. A self-micro emulsifying drug delivery system (SMEDDS). International Journal of Pharmaceutical Science Review and Research. 2010;4(3):29-35.

28. Dissolution Methods Database. U.S. Food and Drug Administration Web. 2019. site.http://www.Fda.gov/drugs/development-resources/dissolution-methodsdatabse-frequently-asked-questions

29. Gupta S, Sawarkar S, Ravikumar P. Solubility enhancement of poorly watersoluble protease inhibitor. International Journal of Pharmaceutical Science and Research. 2016;7(1):252-8.

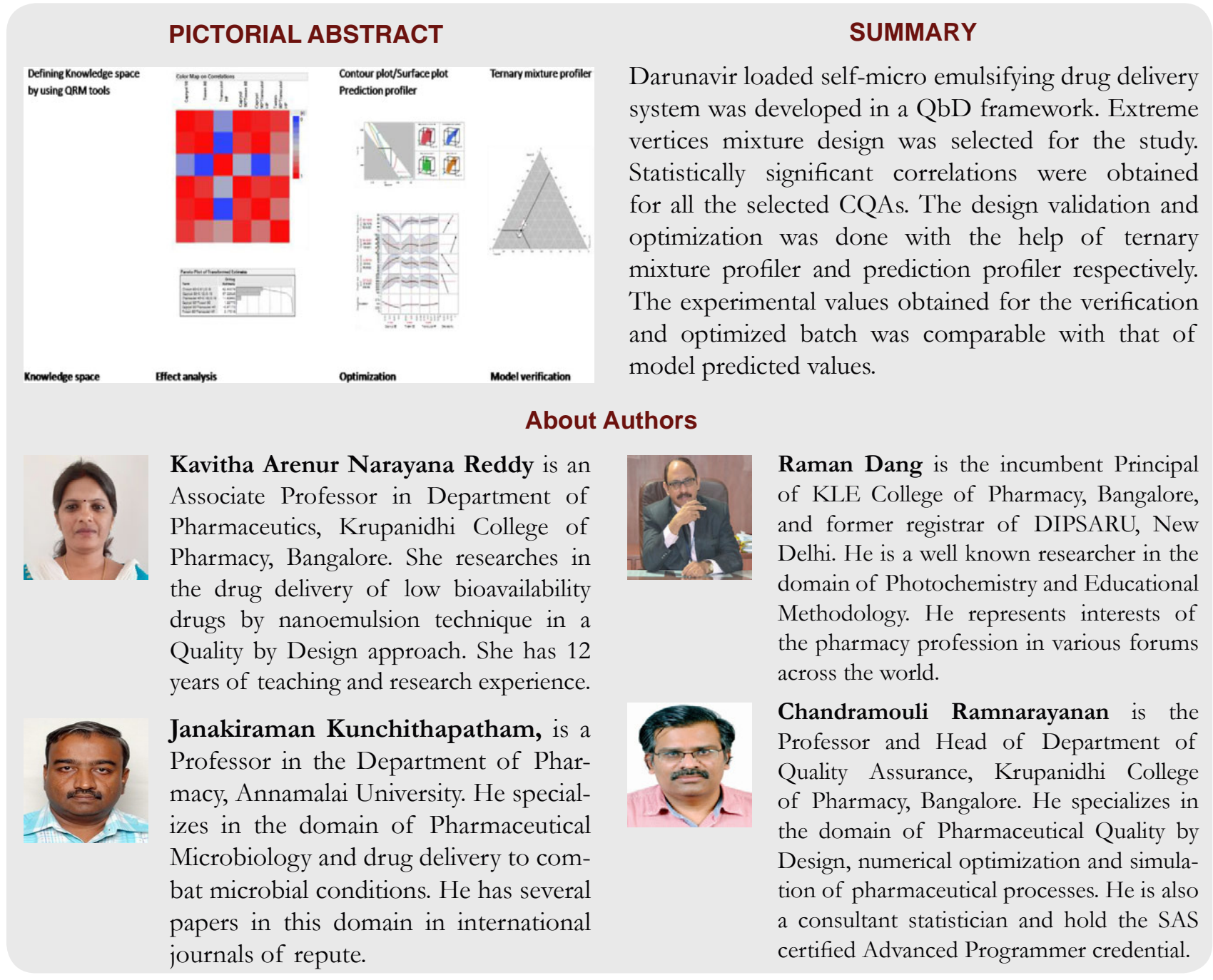

Cite this article: Kavitha AN, Janakiraman K, Dang R, Chandramouli R. Design and Development of Darunavir loaded Self Micro Emulsifying Drug Delivery System using Extreme Vertices Mixture Design in a Quality by Design Framework. Indian J of Pharmaceutical Education and Research. 2020;54(2):337-48. 